\title{
Assessing, understanding and modifying nutritional status, eating habits and physical activity in European adolescents: The HELENA (Healthy Lifestyle in Europe by Nutrition in Adolescence) Study
}

\begin{abstract}
LA Moreno 1,* , M González-Gross ${ }^{2,3}, M$ Kersting ${ }^{4}$, D Molnár 5 , S de Henauw ${ }^{6}$,

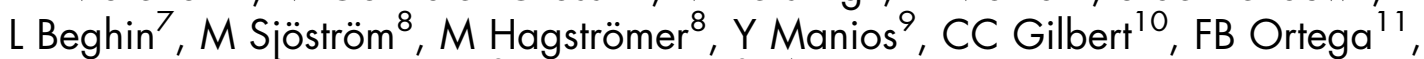

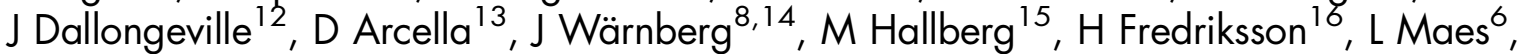
K Widhalm ${ }^{17}$, AG Kafatos ${ }^{18}$ and A Marcos ${ }^{14}$, on behalf of the HELENA Study Group $\dagger$ ${ }^{1}$ Escuela Universitaria de Ciencias de la Salud, Domingo Miral s/n, 50009 Zaragoza, Spain: ${ }^{2}$ Facultad de Ciencias de la Actividad Física y del Deporte, Universidad Politécnica de Madrid, Madrid, Spain: ${ }^{3}$ Institut für Ernährungs- und Lebensmittelwissenschaften, Rheinische Friedrich-Wilhemls Universität Bonn, Bonn, Germany: ${ }^{4}$ Research Institute of Child Nutrition Dortmund, Rheinische Friedrich-Wilhelms-Universität Bonn, Dortmund, Germany: ${ }^{5}$ University of Pécs, Pécs, Hungary: ${ }^{6}$ Ghent University, Ghent, Belgium: ${ }^{7}$ EA-3925 and ClC-9301, Université de Lille 2, Lille, France: ${ }^{8}$ Karolinska Institutet, Huddinge, Sweden: ${ }^{9}$ Department of Nutrition \& Dietetics, Harokopio University, Athens, Greece: ${ }^{10}$ Department of Consumer and Sensory Sciences, Campden \& Chorleywood Food Research Association, Chipping Campden, UK: ${ }^{1}$ Departamento de Fisiología, Facultad de Medicina, Universidad de Granada, Granada, Spain: ${ }^{12}$ Institut Pasteur de Lille, Lille, France: ${ }^{13}$ INRAN National Research Institute for Food and Nutrition, Rome, Italy: ${ }^{14}$ Grupo Inmunonutrición, Departamento de Metabolismo y Nutrición, Instituto del Frio, Consejo Superior de Investigaciones Científicas, Madrid, Spain: ${ }^{15}$ Cederroth International AB, Sweden: ${ }^{16}$ Cerealia R\&D AB, Sweden: ${ }^{17}$ Department of Pediatrics, Division of Clinical Nutrition and Prevention, Medical University of Vienna, Vienna, Austria: ${ }^{18}$ Preventive Medicine \& Nutrition Unit, University of Crete School of Medicine, Heraklion, Crete, Greece
\end{abstract}

Submitted 31 0ctober 2006: Accepted 3 April 2007: First published online 6 July 2007

\begin{abstract}
Objectives: To identify the main knowledge gaps and to propose research lines that will be developed within the European Union-funded 'Healthy Lifestyle in Europe by Nutrition in Adolescence' (HELENA) project, concerning the nutritional status, physical fitness and physical activity of adolescents in Europe.

Design: Review of the currently existing literature.

Results: The main gaps identified were: lack of harmonised and comparable data on food intake; lack of understanding regarding the role of eating attitudes, food choices and food preferences; lack of harmonised and comparable data on levels and patterns of physical activity and physical fitness; lack of comparable data about obesity prevalence and body composition; lack of comparable data about micronutrient and immunological status; and lack of effective intervention methodologies for healthier lifestyles.

Conclusions: The HELENA Study Group should develop, test and describe harmonised and state-of-the-art methods to assess the nutritional status and lifestyle of adolescents across Europe; develop and evaluate an intervention on eating habits and physical activity; and develop and test new healthy food products attractive for European adolescents.
\end{abstract}

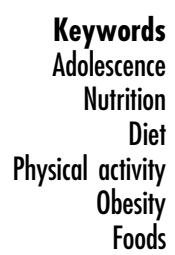

Non-communicable diseases, such as coronary heart disease, stroke, obesity, hypertension, type 2 diabetes mellitus, eating disorders and various cancers, are still the

$†$ See Appendix for a full list of the HELENA Study Group members. most common causes of morbidity and mortality in European countries. These highly prevalent diseases occur in the face of increasing knowledge, awareness and education about chronic diseases and their risk factors. It has been suggested that a paradigm shift is necessary if future progress is to be made ${ }^{1}$. 
Most of these diseases have their origin during childhood and adolescence ${ }^{2-5}$, but the complex relationship between all of these processes and the development of non-communicable diseases is poorly understood in adolescence. Moreover, the interactions between the environment, genetic predisposition and growth in children and adolescents have not yet been studied ${ }^{6}$. Adolescence is a crucial period in life and implies multiple physiological and psychological changes that affect nutritional needs and habits ${ }^{7,8}$.

Existing research indicates that risk factors for noncommunicable diseases have to be placed in an ecological context, which needs a collaborative strategy within the multiple sectors that impact on the diseases?. Inadequate dietary habits and physical inactivity are the major preventable risk factors for the occurrence of non-communicable diseases ${ }^{10}$. The reduction of non-communicable disease risk factors in childhood and adolescence may reduce morbidity and mortality in adulthood.

To identify adolescents at risk and find solutions, known risk markers have to be measured, new biological markers have to be identified and new indices should be developed combining biological and lifestyle/environmental data. This is possible only by conducting research with well-defined study protocols. Up until now, there has been no study at European level that has investigated the nutritional status and lifestyle of adolescents with the same methodology throughout several countries ${ }^{11}$. This is the motivation behind a European Union-funded project entitled 'Healthy Lifestyle in Europe by Nutrition in Adolescence' (HELENA), which commenced on 1 May 2005 (contract number: FOOD-CT-2005-007034) with a budget of $€ 4.99$ million provided by the European Commission. The cross-sectional, multi-centre study AVENA ('Alimentación y Valoración del Estado Nutricional de los Adolescentes Españoles') was designed in 1999 to evaluate the nutritional status of a representative sample of Spanish adolescents $^{12}$. This study can be considered the precursor of the HELENA Study, since the experience acquired in the project has been of great assistance in establishing the HELENA study design and protocol.

The aims of the present review are to identify relevant aspects related to nutrition in the adolescent period, especially where there is lack of comparable data; to propose research lines; and to describe briefly the actions that the HELENA research consortium plans to accomplish.

\section{Food and nutrient intake}

The present dietary data on European children and adolescents are flawed with serious methodological problems ${ }^{13}$. For instance, various collection methods are used and the ages or age cut-off points of the children surveyed are inconsistent. Therefore, there is a need for harmonisation and standardisation of methods to be used in nutrition surveys in children and adolescents in Europe $^{13}$.

In addition, for dietary evaluations each country uses a different set of food composition data which differ in definitions, analytical methods, units and coding. This makes comparisons between countries difficult and inaccurate.

It is well known that adolescents have particular food choices and meal habits compared with younger children and adults ${ }^{14,15}$. Furthermore, a number of validation studies have shown that, in addition to the general problem of misreporting in dietary surveys in children and adolescents, underreporting of energy intake is found more often in adolescents, especially in girls, than in children.

A limited number of dietary assessment instruments that are specifically designed for adolescents have been found to be valid and reproducible. Thus there is a demand for a short, easily administered, inexpensive and accurate instrument that can be used in a broad range of adolescent subpopulations ${ }^{16,17}$ and that should take advantage of modern computer-based dietary assessment tools $^{18}$. For nutritional epidemiological studies in Europe, the EFCOSUM ('European Food Consumption Survey Method') project has proposed to use repeated 24-hour recalls from the age of 10 years onwards ${ }^{19}$.

In summary, there are insufficient data to draw any conclusions about the nutritional quality of the diets of European children and adolescents. The HELENA Study will provide harmonised and comparable data on food intake among male and female European adolescents, taking advantage of a computer-based and attractive dietary assessment tool for 24-hour recalls, with a central standardised protocol. For this purpose, an existing tool called YANA-C (Young Adolescents' Nutrition Assessment on Computer $)^{20}$ has been adapted to local conditions (food lists, portion sizes, etc.) for all participating countries and will be linked to local food composition databases through collaboration with another ongoing Sixth Framework Programme project called EUROFIR ('European Food Information Resource Network'; www.eurofir.net), using a standardised protocol.

\section{Cognitive determinants of eating habits}

Despite the intuitive appeal of education as a means of improving diet, many studies in this area have failed to find significant associations between nutritional knowledge and dietary behaviour ${ }^{21}$. Since the way in which nutrition knowledge transforms into dietary behaviour and nutrient intake may vary among populations, it appears important to assess whether nutrition knowledge is associated with particular food choices and nutrient intakes before any nutrition intervention is initiated in a given population. 
Studies in adults suggest that nutrition knowledge influences dietary behaviour ${ }^{22,23}$. Studies in children and adolescents are scarce. Increasing age and type of school were found to correlate significantly with nutritional knowledge but not with degree of overweight ${ }^{24}$.

Previous studies revealed that large proportions of populations have misconceptions about personal dietary intake levels ${ }^{25,26}$ and may misunderstand general dietary information, e.g. to decrease fat intake. Therefore, personal feedback on dietary intake, such as delivered through computer-tailoring, together with tailored information about food choices, has considerable potential to communicate a personal need to change ${ }^{27}$.

The HELENA Study will provide data about nutrition knowledge, attitudes towards nutrition and the main determinants of food choice and preference, among male and female European adolescents.

\section{Physical activity, exercise and physical fitness}

The detailed relationship between physical activity, fitness, fatness and health in adolescence remains to be clarified. Cross-sectional studies have documented the relationship between physical activity, physical fitness and health, and a number of cardiovascular risk factors already during childhood and adolescence ${ }^{28-30}$. Similarly, longitudinal studies have shown that the degree of physical fitness during childhood and adolescence may determine one's physical fitness as an adult. In addition, poor physical fitness during these stages of life seems to be associated with later cardiovascular risk factors such as hyperlipidaemia, hypertension and obesity ${ }^{31-34}$. Recent observations suggest that preventive efforts focusing on maintaining physical fitness (especially muscular and cardiorespiratory fitness) and physical activity through puberty may have favourable health benefits in later years $^{35}$. The HELENA project has the ambition and potential to explore these relationships further.

Physical activity is a behaviour that is, because of its complex nature, difficult to assess under free-living conditions. No single method is available to quantify all dimensions of the activity (total amount, intensity, frequency, duration, etc.). Lack of comparable data, especially regarding young individuals, hampers the understanding of the complex relationship between these characteristics of physical activity, physical fitness and health outcomes.

Physical fitness encompasses all the physical qualities of a person, among young as well as adult individuals. The state of physical fitness can be considered an integrated part of all of the functions and structures involved in the performance of physical exertion ${ }^{36}$. Health-related physical fitness involves cardiorespiratory fitness, muscle strength, speed and agility, coordination, flexibility and body composition.

Physical activity can be measured using subjective methods, such as questionnaires, or objective methods, such as motion sensors or heart-rate monitors ${ }^{37}$. Motion sensors can be either simple pedometers or more advanced accelerometers. Accelerometers measure the acceleration of the body movement in one or more directions and can quantify physical activity data in terms of time and intensity ${ }^{38,39}$. Accelerometers can store physical activity data for several weeks and have been found to be a valid and reliable measure of intensity, duration and frequency of the physical activity, as well as a measure of total physical activity, in adolescents ${ }^{38}$.

In the HELENA Study, levels and patterns of physical activity are measured using a uniaxial accelerometer. The accelerometer is worn for one week and summarises the physical activity data each time period of $15 \mathrm{~s}$ or more, for every waking hour except during water-based activities.

One advantage - especially in an international setting like that of the HELENA Study - is that an accelerometer does not know any geographical, linguistic or cultural boundaries. However, accelerometers are costly and advanced devices, and even if they provide data of good quality they are not a possible alternative for many research groups and organisations.

The International Physical Activity Questionnaire (IPAQ) was originally developed as an instrument for cross-national monitoring of physical activity and inactivity in adults. The IPAQ instrument has been tested against accelerometers and has been found to have acceptable measurement properties, at least as good as other established self-reports ${ }^{40}$. The HELENA Study will develop and test a questionnaire for use among adolescents, based on the long format of the IPAQ, which will provide internationally comparable data.

The health-related physical fitness components will be assessed by means of the following physical fitness tests (the rationale for the selection of all these tests has been previously published ${ }^{41}$ ):

1. Back-saver sit-and-reach test, to assess flexibility.

2. Handgrip test, to assess maximum handgrip strength.

3. Standing broad jump test, to assess lower-limb explosive strength.

4. Jump tests according to the Bosco protocol (three different jumps) - the squat jump, to assess lower-limb explosive strength; the counter movement jump, to assess lower-limb explosive strength and elastic component assessment; and the Abalakov jump, to assess lower-limb explosive strength, elastic component and inter-muscular coordination capacity assessment.

5. Bent arm hang test, to assess upper-limb endurance strength.

6. Shuttle run test, $4 \times 10 \mathrm{~m}$, to assess speed of movement, agility and coordination.

7. Shuttle run test, $20 \mathrm{~m}$, to assess cardiorespiratory fitness. 
The HELENA Study will provide harmonised and comparable data about physical activity level and patterns, physical fitness and health outcomes among male and female European adolescents, using an objective measure of physical activity and a standardised valid set of fitness measures. In this regard, validation and reliability studies for the physical activity and physical fitness tools used in the HELENA Study are being currently developed. In fact, mathematical equations have already been reported that may improve the reliability and accuracy of the results, and may guide clinicians and researchers in selecting the optimal grip span on the hand dynamometer when measuring handgrip strength in adolescents ${ }^{42}$.

\section{Body composition, obesity and related risk factors in adolescents}

Rates of cardiovascular diseases and diabetes have been found to increase in both men and women who were obese during adolescence ${ }^{43}$. Approximately $50 \%$ of obese adolescents with a body mass index at or above the 95th percentile become obese adults ${ }^{43}$. The prevalence of obesity in US children and adolescents has increased dramatically in the last decades ${ }^{44}$. In Europe, there are few representative data about obesity prevalence in adolescents and the existing ones are not comparable, because different definitions for obesity were used. However, available results point out that there is also a dramatic increase in the prevalence of obesity in European adolescents, with differences according to gender and socio-economic status ${ }^{45}$.

Recently, Lobstein and Frelut ${ }^{46}$ reported estimates of the prevalence of overweight in children and adolescents in various European countries based on 20 surveys with the data recalculated where necessary to conform to international definitions. They detected two apparent trends. The first was the generally lower levels of overweight in the countries of Central and Eastern Europe whose economies suffered varying degrees of recession during the period of economic and political transition in the 1990s. The second trend was for the prevalence of overweight to be higher among the southern countries of Europe, especially those outside the former Eastern Bloc. These data were also included in a very recent report from the International Association of the Study of Obesity's International Obesity Task Force ${ }^{47}$.

In cross-sectional, nationally representative, schoolbased surveys in 1997-1998 that used identical data collection methods, Lissau et al. ${ }^{48}$ assessed overweight prevalences in 13- and 15-year-old adolescents in 13 European countries, Israel and the USA. The highest prevalence was found in the USA and the lowest in Lithuania. The highest prevalences in Europe were found in Ireland, Greece and Portugal.
Very recently, it was observed in a representative sample of Spanish adolescents (AVENA Study) that the rate of change in overweight and obesity prevalences seems to have increased in recent years; from 0.88 (1985 to 1995 ) to $2.33 \%$ per year (1995 to $2000-2002$ ) in males and from 0.5 (1985 to 1995 ) to $1.83 \%$ per year (1995 to 2000-2002) in females ${ }^{49}$. These findings confirm the idea of a real epidemic situation for paediatric obesity in Europe $^{50}$.

The Working Group Report of the Second World Congress of Paediatric Gastroenterology, Hepatology, and Nutrition has recommended that large-scale prospective population studies should incorporate careful anthropometric measurements and regular monitoring of selected obesity-associated complications using some or all of the following tests: fasting blood tests (glucose, insulin, lipids, liver function tests), blood pressure measurement, glucose tolerance tests, liver ultrasound, measurements of psychosocial functioning, lung function tests, and biomechanical or podiatric assessment ${ }^{51}$.

Atherosclerosis starts in childhood and adolescence, but clinical manifestations can appear 30 to 50 years later. This is the reason why it is so important to identify risk factors as early as possible. Risk factors for several of the major chronic diseases, such as cardiovascular diseases, hypertension, diabetes, obesity and cancer, are often observed during childhood. Metabolic syndrome seems to be present already during adolescence, especially if there is a predisposing genetic background. Prevalence of multimetabolic syndrome among obese children and adolescents in Hungary was $7.7 \%$ for boys and $9.1 \%$ for girls. Only $14.4 \%$ of the obese children and adolescents were free from any cardiovascular risk factors ${ }^{52}$.

Adolescents at risk for this condition could easily be identified $^{53}$. Unfortunately no consensus concerning the definition of the metabolic syndrome in childhood has been established ${ }^{54}$. Therefore the results of those few studies investigating the prevalence of the metabolic syndrome in childhood as a primary goal are not comparable.

A growing body of evidence implicates adipose tissue as a key regulator of inflammation, and chronic, subclinical inflammation implicated in the pathophysiological mechanisms of atherosclerotic disease has already been observed in adolescence ${ }^{55}$. The inflammatory biomarkers selected for this study are sensitive enough to investigate the health of European adolescents and to establish determinants for chronic inflammation caused by unhealthy body weight or nutritional and physical activity habits.

The HELENA Study will provide comparable data on body composition, blood lipids, fasting glucose, insulin, adiponectin, leptin and blood pressure, in order to establish the prevalence of obesity and analyse the clustering of cardiovascular risk factors (metabolic syndrome) among male and female European adolescents. 


\section{Micronutrient status in adolescents}

In developed countries, nutritional studies dealing with vitamin and mineral status are facing new challenges. In spite of the huge availability and variety of foods and the possibility of good nutrition, malnutrition is affecting several population subgroups for selected nutrients, with adolescents being one of these groups at risk $^{56}$. Similar to the situation mentioned in other parts of this review, representative data are lacking for most micronutrients in Europe. In addition, the lack of reference values for adolescents for most of the blood parameters makes the analysis of available data quite difficult, as adult reference values have to be used. Several review articles have tried to establish micronutrient status in European adolescents ${ }^{13,57}$. With the necessary caution that arises when analysing data from different studies performed with different methodologies, there seems to be an agreement that folate ${ }^{57-60}$, calcium $^{14,15,56}$, vitamin $\mathrm{D}^{61,62}$ and iron ${ }^{63}$ are nutrients at risk in the adolescent population in most of the countries.

Another aspect that needs more in-depth study is the possible differences in vitamin and mineral status by gender. As Bergstrom et al. ${ }^{64}$ established in Swedish adolescents, the differences in iron status between boys and girls result primarily from biological differences other than menstrual bleeding or insufficient iron intake. In the UK, adolescent girls showed the highest prevalence of low iron intake and poor iron status, with the latter independently associated with non-Caucasian ethnicity and vegetarianism ${ }^{65}$. Several studies show serum cobalamin values to be higher in girls than in boys ${ }^{57,66}$. The concentration of total homocysteine in serum and plasma is elevated in both folate and cobalamin deficiencies. High homocysteine levels are associated with an increased risk of several chronic diseases in adulthood, such as cardiovascular diseases and dementia, and are higher in adolescent males than in females ${ }^{66,67}$. The risk of high homocysteine levels in adolescence must be established, although available data seem to indicate that they correlate with poorer cardiovascular fitness ${ }^{68}$ and increased risk for future chronic diseases.

Dietary intake of nutrients does not always correlate with serum values. Serum ferritin and serum transferrin receptor concentrations, growth and food habits were studied in healthy Swedish boys and girls at the age of 17 years and compared with those in the same adolescents at age 15 . The results indicate insufficient iron stores in the 17-year-old girls in relation to erythropoiesis and iron needs, but more favourable iron stores in the boys. The absence of a significant decrease in mean serum ferritin despite rapid growth suggests that the earlier iron fortification of flour only marginally contributed to the iron status of Swedish adolescents of this age group ${ }^{69}$. It has been proposed that risk of poor iron status could be reduced by consuming (particularly lean red) meat or enhancers of non-haem iron absorption (e.g. fruit or fruit juice) in vegetarians ${ }^{65}$. Although research suggests that adolescents, particularly girls, may avoid dairy products due to concerns that these foods are 'fattening', avoidance of dairy foods due to a possible association with relative body weight is not supported by the available results ${ }^{70}$. In Finnish peripubertal girls, vitamin D supplementation daily with $20 \mu \mathrm{g}$ is needed to prevent hypovitaminosis $\mathrm{D}$ in winter. Sunlight exposure in summer is more effective than approximately $20 \mathrm{mg}$ of vitamin $\mathrm{D}_{2}$ supplementation daily in winter to raise serum 25-hydroxyvitamin D levels. Both the daily supplementation with $20 \mathrm{mg}$ of vitamin $\mathrm{D}_{2}$ and summertime sunlight exposure had more effect on those who had severe hypovitaminosis $\mathrm{D}$ than in those who had a normal vitamin D status ${ }^{61,62}$. Pubertal girls with hypovitaminosis $D$ seem to be at risk of not reaching maximum peak bone mass, particularly at the lumbar spine. Dietary enrichment or supplementation with vitamin D should be considered to ensure an adequate vitamin D status $^{61,62}$. A positive association between dietary calcium/phosphorus ratio and markers of collagen formation (N-terminal propeptide of type 1 collagen) has been observed. This relationship can be attributable to a higher calcium intake per se, a critical balance between calcium and phosphorus intake, or high dairy product consumption. A higher incidence of vitamin D insufficiency in older adolescents may reflect a more sedentary lifestyle or increased utilisation of 25-hydroxyvitamin $\mathrm{D}^{71}$.

The voluntary addition of micronutrients to the appropriate foods may help address the risks associated with low micronutrient intakes. Folic acid fortification of food has shown to be responsible for about $25 \%$ of folate intake in the German adolescent population ${ }^{59}$. Folic acid fortification could be the explanation for the differences observed between folate intake and blood values. Folate intake from fortified food or from supplements is not taken into account in most of the studies, which is a variable that can lead to confusion. Nutrition surveys should include fortified commercial foods in their composition tables, in order to make folate intake more accurate. However, concerns need to be addressed regarding the potential for unacceptably high intakes, particularly for those people consuming very large amounts of food $^{72}$, as it is in adolescents.

It is accepted that food and nutrient intake data are not enough to establish nutritional status and must be complemented with biochemical data. For micronutrient status, it is necessary to establish reference values obtained in large population samples analysed under the same methodological conditions. This will permit a correct interpretation of results in further nutritional studies. As there have not been any nutritional studies on 
adolescents performed at European level (as proposed in HELENA), these reference values and cut-off points for most parameters, and specifically for vitamins, are missing.

\section{Immunological characteristics related to nutritional status}

The study of nutritional immunology is a relatively new discipline; however, it is widely accepted that normal functioning of the immune system is crucial for health and that diet is one of the major exogenous factors modulating individual immunocompetence. Malnutrition causes significant alteration in immune response but even subclinical deficits may be associated with an impaired immune response, which makes immune parameters sensitive biomarkers of nutritional status ${ }^{73,74}$.

A growing body of evidence implicates inflammatory markers in pathophysiological mechanisms of chronic diseases such as atherosclerotic diseases, diabetes, obesity, cancer, allergies, arthritis and rheumatic diseases. These associations have mainly been studied in adults or diseased subjects, but moderately increased levels of novel risk markers, such as the ones that will be examined in the HELENA Study, have also been found during past years in young populations with no apparent ongoing chronic disease.

Confirming several studies, including a larger American study in children ${ }^{75}$, the AVENA Study showed that overweight is associated with higher production of inflammatory proteins, characterising this otherwise apparently healthy young overweight population by a state of chronic low-grade inflammation ${ }^{55,76}$. There is also increasing evidence to show that chronic subclinical inflammation is associated with metabolic dysfunction, which links causally to insulin resistance and the metabolic syndrome in adolescents ${ }^{77}$. Dietary factors such as fatty acids, antioxidants or fibre can potentially modulate the association between adiposity and subclinical inflammation $^{78,79}$, as can physical activity and fitness ${ }^{80}$, but more studies of the determinants of subclinical inflammation in this age group are needed to clarify how a healthier lifestyle affects these novel risk markers.

The interpretation of immunological markers depends critically on knowledge of the behaviour of normal adolescent immune function, as well as the understanding of determinants of variability. While there are substantial data on immune measures and functioning among the adult and newborn population and more recently in the elderly, there has been little research on immunonutrition in young populations. The HELENA Study will provide nutrition scientists with reference values of immunological parameters for future research on the nutritional status of European adolescents. As all laboratory assessments will be centralised, the HELENA Study will provide unique comparable immunological data related to the nutritional status in European adolescents.

\section{Nucleotide polymorphisms and phenotype heterogeneity}

The molecular pathogenesis of paediatric obesity remains unknown for the vast majority of overweight children and adolescents. More than 100 candidate genes or regions are potentially implicated ${ }^{81}$. Single formal genetic studies suggest a higher heritability of body weight in adolescence and genes that influence body weight in adulthood might not be the same as those that are relevant in childhood and adolescence. Multiple measurements of body mass index from childhood to adulthood in white siblings showed considerably greater heritability than a cross-sectional measurement. Significant and suggestive linkage with long-term burden and trend of body mass index was observed on chromosomes 1, 5, 7, 12, 13 and 18. Candidate genes involved in the pathophysiology of obesity are identified in all regions on six chromosomes except for $7 \mathrm{q} 11.1^{82}$.

Some individuals appear to be relatively sensitive to dietary or lifestyle intervention, whereas others are quite insensitive. There is strong evidence that variability to changes in environmental factors is partly determined by genetic factors. This can be relevant for obesity at least at three different levels: they could be involved in determining the susceptibility to gain fat in response to environmental risk factors (high-fat diet, low physical activity, etc.); they may influence the response of the phenotype to interventions; and they can be involved in the susceptibility of obese individuals to develop co-morbidities associated with obesity.

There are more than 430 chromosomic regions with gene variants involved in body weight regulation and obesity development. Polymorphisms in genes related to energy expenditure (such as uncoupling proteins), adipogenesis and insulin resistance (such as hormonesensitive lipase, peroxisome proliferator-activated receptor- $\gamma, \beta$-adrenergic receptors 2 and 3 and tumour necrosis factor- $\alpha$ ) and food intake (such as ghrelin) appear to be associated with obesity phenotypes.

The genotype-environment interactions could also be involved in the susceptibility of obese individuals to develop co-morbidites associated with obesity (diabetes, hyperlipidaemia, hypertension and coronary heart disease). Definition of these interaction effects for phenotypes related to obesity is therefore important because it will eventually allow the identification of individuals at risk for the development of complications and the identification of those likely to be resistant to dietary interventions. The study of these genetic markers in adolescents and their relationship to several phenotypic characteristics of the population will permit a better 
understanding of the pathogenic mechanisms that are involved in non-communicable diseases, specifically cardiovascular diseases.

There are also several genetic factors which determine blood lipid profile, specifically several apoproteins. These apoproteins, which are synthesised by polymorphic genes, present several isoforms which are relatively frequent among the population and can influence blood lipid profile by interacting with specific exogenous factors like dietary habits.

The HELENA Study will provide data on the relationship between genetic markers and phenotypic characteristics among male and female European adolescents. Two major lines of investigation will be developed. The first will test whether single-nucleotide polymorphisms, located in genes related to energy expenditure, adipogenesis, insulin resistance and food intake, interact with indicators of physical activity to explain part of body mass composition variability in adolescents. The second will look for possible interactions between known singlenucleotide polymorphisms in genes involved in plasma lipid and glucose homeostasis, and blood pressure regulation and body composition, in the regulation of major cardiovascular risk factors and components of the metabolic syndrome in adolescents.

\section{Food preferences and development of new healthy foods}

There are many concerns surrounding adolescent food choice behaviour, including low intake of fruits and vegetables, and high intake of foods that are high in fat, sugar and salt ${ }^{15,83,84}$. Reasons for these preferences and consumption patterns can range from innate food preferences and familiarity ${ }^{85,86}$ to social and environmental influences ${ }^{87}$.

Although many adolescents demonstrate awareness and knowledge of nutrition and healthy eating, it does appear they find it difficult putting this theory into practice $^{84,86,88,89}$.

A lack of understanding about how to communicate dietary messages effectively is hindering the innovation of products that can contribute to consumer health, wellbeing and enhanced industrial competitiveness ${ }^{90}$. Smalland medium-sized enterprises play an important role in producing the great diversity of foods in Europe and the retail sector increasingly contributes to strengthening the links between production, processing and the consumer. Therefore, there is a need to better understand consumer requirements and preferences, and to provide a healthy, safe and high-quality food supply - in this case, specifically for adolescents.

There are a multitude of factors that can influence adolescent food choices and preferences. In general terms these may include availability, convenience, cost, influence of peers, parents, hunger and health concerns $^{87-89}$. However, one of the most important determinants of food choice is the adolescents' food preferences. Taste, in particular, plays an important role in food choice. Generally speaking, adolescents won't eat what they don't like ${ }^{84,86-88}$.

The HELENA Study will seek to further understand the impact of these and other factors on adolescent food choices and preferences, and utilise this information to guide the development of healthy new food products. In particular, given that adolescents are highly driven by taste, close attention needs to be given to the sensory aspects of the newly developed food products.

In addition to understanding the opinions and views of the adolescents themselves, a multidisciplinary research effort bringing together a wide range of expertise is essential to address the whole problem surrounding nutrition and lifestyle of adolescents in Europe. The HELENA consortium will also develop new healthy foods, attractive for male and female European adolescents. One of these foods will be a low-glycaemic, highfibre biscuit.

The glycaemic index has proved to be a useful nutritional concept, providing new insights into the relationship between foods and chronic disease ${ }^{91}$. Observational studies suggest that diets with a high glycaemic load are independently associated with increased risk of type 2 diabetes and cardiovascular diseases ${ }^{92}$. Some evidence suggests that a low-glycaemic-index diet may also protect against obesity, colon cancer and breast cancer. In adolescents, the effect of an ad libitum, reduced-glycaemicload diet has been compared with that of an energyrestricted, reduced-fat diet; at 12 months, body mass index and fat mass decreased more in the low-glycaemicindex diet compared with the reduced-fat diet. In post hoc analyses, the glycaemic load was a significant predictor of treatment response among both groups, whereas dietary fat was not ${ }^{33}$.

Low-glycaemic-index diets influence body weight and resting energy expenditure independently of caloric intake. In a short cross-over study, Agus et al. ${ }^{94}$ compared a high-glycaemic-index, energy-restricted diet with an isocaloric, low-glycaemic-index diet in moderately overweight young men and showed that resting energy expenditure declined by $10.5 \%$ on the former diet compared with $4.6 \%$ on the latter diet.

\section{Interventions on eating habits and physical activity}

Most studies dealing with nutritional status and physical activity among European adolescents conclude that nutritional interventions and interventions to enhance physical activity are strongly needed ${ }^{95,96}$. 
School-based health and nutrition education intervention studies in Europe and the USA have had mixed results in effecting physiological changes ${ }^{97,98}$. The majority of trials have been conducted in the USA, and there are doubts whether these can be extrapolated to the great diversity of the European area ${ }^{99}$.

New and modern tools for health promotion in adolescents need to be developed focusing on this specific population and considering gender differences. Adolescence is a unique period in life. Health promotion should not force models of behaviour onto individuals or groups. Adolescents need a food culture based on foods to eat, rather than foods to avoid, and an understanding of suitable weight-control measures ${ }^{100}$. Computer-tailored nutrition and physical activity education is an innovative, promising and cost-effective tool to motivate people to make healthy dietary and physical activity changes. It provides respondents with individualised feedback about dietary behaviour and physical activity. The available evidence indicates that computer-tailored education is more effective in motivating people to make changes than general nutritional and physical activity education $^{101}$. Until now most computer-tailored nutrition programmes have focused on one or a few aspects of nutrition behaviour such as fat intake or fruit and vegetable intake. Most programmes are aimed at adults. The present project will develop and evaluate a web-based intervention focusing on the usual eating and physical activity habits of adolescents. Adolescents will be stimulated to use the web-based intervention by teachers in schools; the first use of the intervention will take place during class time. For further use the intervention will be available on the web. The diet optimisation approach, not used until now in computer-tailored interventions, will make it possible to write an individualised advice to optimise the usual eating habits of adolescents. To date, there is no experience in the assessment of the efficacy of such a tool in Europe.

\section{Conclusions}

The main gaps in the knowledge concerning the nutritional status situation in European adolescents are: lack of harmonised and comparable data on food intake; lack of understanding regarding the role of eating attitudes, food choices and food preferences; lack of harmonised and comparable data on physical activity and physical fitness; lack of comparable data about obesity prevalence and body composition; and lack of comparable data about micronutrient status. Given the above-mentioned problems, the HELENA Study Group plans to describe the nutritional status of the adolescents in Europe, and to improve health-related nutritional aspects by proposing an innovative educational intervention and developing new healthy foods attractive for European adolescents.

\section{Acknowledgements}

Sources of funding: The HELENA Study takes place with the financial support of the European Community Sixth RTD Framework Programme (Contract FOOD-CT2005-007034). The content of this article reflects only the author's views and the European Community is not liable for any use that may be made of the information contained herein.

F.B.O. is supported by CSD (Ref: 109/UPB31/03 and 13/UPB20/04) and FPU-Spanish Ministry of Education (Ref: AP-2004-2745) grants.

Conflict of interest declaration: None.

Authorship responsibilities: All of the manuscript authors contributed significantly to the conception and design of the paper, drafting or revising it critically for important intellectual content, and approved the final version to be published.

\section{References}

1 Egger G, Swinburn B. An 'ecological' approach to the obesity pandemic. British Medical Journal 1997; 315: 477-80.

2 Moreno LA, Sarría A, Fleta J, Rodríguez G, Bueno M. Trends in body mass index and overweight prevalence among children and adolescents in the region of Aragón (Spain) from 1985 to 1995. International Journal of Obesity and Related Metabolic Disorders 2000; 24: 925-31.

3 Weiss R, Dufour S, Taksali SE, Tamborlane WV, Petersen $\mathrm{KF}$, Bonadonna RC, et al. Prediabetes in obese youth: a syndrome of impaired glucose tolerance, severe insulin resistance, and altered myocellular and abdominal fat partitioning. Lancet 2003; 362: 951-7.

4 Cook S, Weitzman M, Auinger P, Nguyen M, Dietz WH. Prevalence of a metabolic syndrome phenotype in adolescents. Findings from the Third National Health and Nutrition Examination Survey, 1988-1994. Archives of Pediatrics \& Adolescent Medicine 2003; 157: 821-7.

5 Marcos A. Eating disorders: a situation of malnutrition with peculiar changes in the immune system. European Journal of Clinical Nutrition 2000; 54(Suppl. 1): S61-4.

6 Pietrobelli A, Steinbeck KS. Paediatric obesity: what do we know and are we doing the right thing? International Journal of Obesity and Related Metabolic Disorders 2004; 28: 2-3.

7 Forsen T, Osmond C, Eriksson JG, Barker DJ. Growth of girls who later develop coronary heart disease. Heart 2004; 90: $20-4$.

8 Rodríguez G, Moreno LA, Blay MG, Blay VA, Garagorri JM, Sarría A, et al. Body composition in adolescents: measurements and metabolic aspects. International Journal of Obesity and Related Metabolic Disorders 2004; 28(Suppl. 3): $554-8$.

9 Moreno LA, Tomás C, González-Gross M, Bueno G, PérezGonzález JM, Bueno M. Micro-environmental and sociodemographic determinants of childhood obesity. International Journal of Obesity and Related Metabolic Disorders 2004; 28(Suppl. 3): S16-20.

10 Rodríguez $\mathrm{G}$, Moreno LA. Is dietary intake able to explain differences in body fatness in children and adolescents? Nutrition, Metabolism, and Cardiovascular Diseases 2006; 16: 294-301. 
11 Matthys C, De Henauw S, Devos C, De Backer G. Estimated energy intake, macronutrient intake and meal pattern of Flemish adolescents. European Journal of Clinical Nutrition 2003; 57: 366-75.

12 González-Gross M, Castillo MJ, Moreno LA, Nova E, González-Lamuño D, Pérez-Llamas F, et al. Alimentación y valoración del estado nutricional de los adolescentes españoles (Estudio AVENA). Evaluación de riesgos y propuesta de intervención. I. Descripción metodológica del proyecto. Nutrición Hospitalaria 2003; 18: 15-28.

13 Lambert J, Agostoni C, Elmadfa I, Hulshof KFAM, Krause E, Livingstone B, et al. Dietary intake and nutritional status in children and adolescents in Europe. British Journal of Nutrition 2004; 92(Suppl. 2): S147-211.

14 Hoglund D, Samuelson G, Mark A. Food habits in Swedish adolescents in relation to socioeconomic conditions. European Journal of Clinical Nutrition 1998; 52: 784-9.

15 Alexy U, Sichert-Hellert W, Kersting M. Fifteen-year time trends in energy and macronutrient intake in German children and adolescents: results of the DONALD study. British Journal of Nutrition 2002; 87: 595-604.

16 Rockett HR, Berkey CS, Colditz GA. Evaluation of dietary assessment instruments in adolescents. Current Opinion in Clinical Nutrition and Metabolic Care 2003; 6: 557-62.

17 Moreno LA, Kersting M, de Henauw S, González-Gross M, Sichert-Hellert W, Matthys C, et al. How to measure dietary intake and food habits in adolescence: the European perspective. International Journal of Obesity 2005; 29(Suppl. 2): S66-77.

18 Bakker I, Twisk JWR, van Mechelen W, Mensink GBM, Kemper HCG. Computerization of a dietary history interview in a running cohort; evaluation within the Amsterdam Growth and Health Longitudinal Study. European Journal of Clinical Nutrition 2003; 57: 394-404.

19 Biro G, Hulshof KFAM, Ovesen L, Amorin Cruz JA, for the EFCOSUM Group. Selection of methodology to assess food intake. European Journal of Clinical Nutrition 2002; 56(Suppl. 2): S25-32.

20 Vereecken CA, Covents M, Matthys C, Maes L. Young adolescents' nutrition assessment on computer (YANA-C). European Journal of Clinical Nutrition 2005; 59: 658-67.

21 Parmenter K, Wardle J. Development of a general nutrition knowledge questionnaire for adults. European Journal of Clinical Nutrition 1999; 53: 298-308.

22 Wardle J, Parmenter K, Waller J. Nutrition knowledge and food intake. Appetite 2000; 34: 269-75.

23 Dallongeville J, Marécaux N, Cottel D, Bingham A, Amouyel P. Association between nutrition knowledge and nutritional intake in middle-aged men from Northern France. Public Health Nutrition 2000; 4: 27-33.

24 Reinehr T, Kersting M, Chahda C, Andler W. Nutritional knowledge of obese compared to non obese children. Nutrition Research 2003; 23: 645-9.

25 Brug J, Hospers H, Kok G. Differences in psychosocial factors and fat consumption between stages of change for fat reduction. Psychology \& Health 1997; 12: 719-27.

26 Brug J, Van Assema P, Kok G, Lenderink T, Glanz K. Selfrated dietary fat intake: association with objective assessment of fat, psychosocial factors and intention to change. Journal of Nutrition Education 1994; 26: 218-23.

27 De Bourdeaudhuij I, Brug J. Tailoring dietary feedback to reduce fat intake: an intervention at the family level. Health Education Research 2000; 15: 449-62.

28 Ekelund U, Poortvliet E, Nilsson A, Yngve A, Holmberg A, Sjostrom M. Physical activity in relation to aerobic fitness and body fat in 14- to 15-year-old boys and girls. European Journal of Applied Physiology 2001; 85: 195-201.

29 Nielsen GA, Andersen LB. The association between high blood pressure, physical fitness, and body mass index in adolescents. Preventive Medicine 2003; 36: 229-34.
30 Wedderkopp N, Froberg K, Hansen HS, Riddoch C, Andersen LB. Cardiovascular risk factors cluster in children and adolescents with low physical fitness: The European Youth Heart Study (EYHS). Pediatric Exercise Science 2003; 15: 419-27.

31 Boreham C, Twisk J, Murray L, Savage M, Strain JJ, Cran G. Fitness, fatness, and coronary heart disease risk in adolescents: the Northern Ireland Young Hearts Project. Medicine and Science in Sports and Exercise 2001; 33: 270-4.

32 Boreham C, Twisk J, Neville C, Savage M, Murray L, Gallagher A. Associations between physical fitness and activity patterns during adolescence and cardiovascular risk factors in young adulthood: The Northern Ireland Young Hearts Project. International Journal of Sports Medicine 2002; 23(Suppl. 1): 22-6.

33 Hasselstrøm H, Hansen SE, Froberg K, Andersen LB. Physical fitness and physical activity during adolescence as predictors of cardiovascular disease risk in young adulthood. Danish youth and sports study. An eight-year follow-up study. International Journal of Sports Medicine 2002; 23(Suppl. 1): 27-31.

34 Janz KF, Dawson JD, Mahoney LT. Increases in physical fitness during childhood improve cardiovascular health during adolescence: the Muscatine Study. International Journal of Sports Medicine 2002; 23(Suppl. 1): 15-21.

35 Janz KF, Dawson JD, Mahoney LT. Tracking physical fitness and physical activity from childhood to adolescence: The Muscatine Study. Medicine and Science in Sports and Exercise 2000; 32: 1250-7.

36 Castillo MJ, Ortega FB, Ruiz JR. La mejora de la forma física como terapia anti-envejecimiento. Medicina Clínica 2005; 124: $146-55$.

37 Sjöström M, Ekelund U, Yngve A. Assessment of physical activity. In: Gibney MJ, Margetts BM, Kearney JM, Arab L, eds. Public Health Nutrition. The Nutrition Society Textbook Series. Oxford: Blackwell Publishing, 2004; 83-105.

38 Esliger DW, Copeland JL, Barnes JD, Tremblay MS Standardizing and optimizing the use of accelerometer data for free-living physical activity monitoring. Journal of Physical Activity and Health 2005; 2: 366-83.

39 Trost SG, McIver KL, Pate RR. Conducting accelerometerbased activity assessment in field-based research. Medicine and Science in Sports and Exercise 2005; 37(Suppl. 11): S531-43.

40 Craig CL, Marshall AL, Sjöström M, Bauman AE, Booth ML, Ainsworth BE, et al. International physical activity questionnaire: 12-country reliability and validity. Medicine and Science in Sports and Exercise 2003; 35: 1381-95.

41 Ruiz JR, Ortega FB, Gutierrez A, Meusel D, Sjöström M, Castillo MJ. Health-related fitness assessment in childhood and adolescence; a European approach based on the AVENA, EYHS and HELENA studies. Journal of Public Health 2006; 14: 269-77.

42 Ruiz JR, Espana-Romero V, Ortega FB, Sjostrom M, Castillo MJ, Gutierrez A. Hand span influences optimal grip span in male and female teenagers. Journal of Hand Surgery 2006; 31: $1367-72$.

43 Dietz WH. Childhood weight affects adult morbidity and mortality. Journal of Nutrition 1998; 128(2 Suppl.): 411S-14S.

44 Ogden CL, Flegal KM, Carroll MD, Johnson CL. Prevalence and trends in overweight among US children and adolescents, 1999-2000. JAMA: Journal of the American Medical Association 2002; 288: 1728-32.

45 Moreno LA, Sarría A, Fleta J, Rodríguez G, Pérez-González JM, Bueno M. Sociodemographic factors and trends on overweight prevalence in children and adolescents in Aragón (Spain) from 1985 to 1995. Journal of Clinical Epidemiology 2001; 54: 921-7. 
46 Lobstein T, Frelut ML. Prevalence of overweight among children in Europe. Obesity Reviews 2003; 4: 195-200.

47 Lobstein $\mathrm{T}$, Baur L, Uauy $\mathrm{R}$ for the IASO International Obesity Task Force. Obesity in children and young people: a crisis in public health. Obesity Reviews 2004; 5(Suppl. 1): $4-85$.

48 Lissau I, Overpeck MD, Ruan J, Due P, Holstein BE, Hediger ML and the Health Behaviour in School-aged Children Obesity Working Group. Body mass index and overweight in adolescents in 13 European countries, Israel, and the United States. Archives of Pediatrics \& Adolescent Medicine 2004; 158: 27-33.

49 Moreno LA, Mesana MI, Fleta J, Ruiz JR, González-Gross MM, Sarría A, et al. and the AVENA Study Group. Overweight, obesity and body fat composition in Spanish adolescents. The AVENA Study. Annals of Nutrition \& Metabolism 2005; 49: 71-6.

50 Jackson-Leach R, Lobstein T. Estimated burden of paediatric obesity and co-morbidities in Europe. Part 1. The increase in the prevalence of child obesity in Europe is itself increasing. International Journal of Pediatric Obesity 2006; 1: 26-32.

51 Fisberg M, Baur L, Chen W, Hoppin A, Koletzko B, Lau D, et al. Obesity in children and adolescents: Working Group Report of the Second World Congress of Pediatric Gastroenterology, Hepatology, and Nutrition. Journal of Pediatric Gastroenterology and Nutrition 2004; 39: S678-87.

52 Csábi G, Török K, Jeges S, Molnár D. Presence of metabolic cardiovascular syndrome in obese children. European Journal of Pediatrics 2000; 159: 91-4.

53 Moreno LA, Pineda I, Rodríguez G, Fleta J, Sarría A, Bueno M. Waist circumference for the screening of the metabolic syndrome in children. Acta Paediatrica 2002; 91: $1307-12$.

54 Molnár D. Prevalence of the metabolic syndrome and type 2 diabetes mellitus in obese children and adolescents. International Journal of Obesity and Related Metabolic Disorders 2004; 28(Suppl. 3): S70-4.

55 Wärnberg J, Moreno L, Mesana MI, Marcos A and the AVENA group. Inflammatory status in overweight and obese Spanish adolescents. The AVENA study. International Journal of Obesity and Related Metabolic Disorders 2004; 28(Suppl. 3): S54-8.

56 Casas J, González-Gross M, Marcos A. Nutrición del adolescente. In: Tojo $\mathrm{R}$, ed. Tratado de Nutrición en Pediatría. Barcelona: Ediciones Doyma, 2000; 437-53.

57 Al-Tahan J, González-Gross M, Pietrzik K. B-vitamin status and intake in European adolescents. A review of the literature. Nutrición Hospitalaria 2006; 21: 452-65.

58 Serra-Majem L, Ribas L, Ngo J, Aranceta J, Garaulet M, Carazo E, et al. Risk of inadequate intakes of vitamins B, $\mathrm{B}_{1}, \mathrm{~B}_{6}, \mathrm{C}, \mathrm{E}$, folate, iron and calcium in the Spanish population aged 4 to 18. International Journal for Vitamin and Nutrition Research 2001; 71: 325-31.

59 González-Gross M, Prinz-Langenohl R, Pietrzik K. Folate status in Germany 1997-2000. International Journal for Vitamin and Nutrition Research 2002; 72: 351-9.

60 McNulty H, Eaton-Evans J, Cran G, Woulahan G, Boreham C, Savage JM, et al. Nutrient intakes and impact of fortified breakfast cereals in schoolchildren. Archives of Disease in Childhood 1996; 75: 474-81.

61 Lehtonen-Veromaa M, Mottonen T, Nuotio I, Irjala K, Viikari J. The effect of conventional vitamin $\mathrm{D}(2)$ supplementation on serum $25(\mathrm{OH}) \mathrm{D}$ concentration is weak among peripubertal Finnish girls: a 3-y prospective study. European Journal of Clinical Nutrition 2002; 56: 431-7.

62 Lehtonen-Veromaa M, Mottonen T, Nuotio I, Irjala K, Leino $\mathrm{AE}$, Viikari J. Vitamin D and attainment of peak bone mass among peripubertal Finnish girls: a 3-y prospective study. American Journal of Clinical Nutrition 2002; 76: 1446-53.

63 Samuelson G, Bratteby LE, Berggren K, Elverby JE, Kempe B. Dietary iron intake and iron status in adolescents. Acta Paediatrica 1996; 85: 1033-8.

64 Bergstrom E, Hernell O, Lonnerdal B, Persson LA. Sex differences in iron stores of adolescents: what is normal? Journal of Pediatric Gastroenterology and Nutrition 1995; 20: $215-24$.

65 Thane CW, Bates CJ, Prentice A. Risk factors for low iron intake and poor iron status in a national sample of British young people aged 4-18 years. Public Health Nutrition 2003; 6: 485-96.

66 Al-Tahan J, Sola R, Ruiz JR, Breidenassel C, García-Fuentes $\mathrm{M}$, Moreno LA, et al. Cobalamin, folate and homocysteine status in Spanish adolescents. Annals of Nutrition $\&$ Metabolism (submitted).

67 Borke AL, Ueland PM. Homocysteine and methylmalonic acid in diagnosis and risk assessment from infancy to adolescence. American Journal of Clinical Nutrition 2003; 78: 7-21.

68 Ruiz JR, Sola R, González-Gross M, Ortega FB, VicenteRodríguez G, García-Fuentes $\mathrm{M}$, et al. Cardiovascular fitness is negatively associated with homocysteine levels in female Spanish adolescents. Archives of Pediatrics \& Adolescent Medicine 2007; 161: 166-71.

69 Samuelson G, Lonnerdal B, Kempe B, Elverby JE, Bratteby LE. A study of serum ferritin and transferrin receptor concentrations in Swedish adolescents at age 17 and age 15. Acta Paediatrica 2000; 89: 1162-8.

70 Phillips SM, Bandini LG, Cyr H, Colclough-Douglas S, Naumova E, Must A. Dairy food consumption and body weight and fatness studied longitudinally over the adolescent period. International Journal of Obesity and Related Metabolic Disorders 2003; 27: 1106-13.

71 Ginty F, Cavadini C, Michaud PA, Burckhardt P, Baumgartner M, Mishra GD, et al. Effects of usual nutrient intake and vitamin D status on markers of bone turnover in Swiss adolescents. European Journal of Clinical Nutrition 2004; 58: $1257-65$.

72 Flynn A, Moreiras O, Stehle P, Fletcher RJ, Muller DJ, Rolland V. Vitamins and minerals: a model for safe addition to foods. European Journal of Nutrition 2003; 42: 118-30.

73 Marcos A, Nova E, Montero A. Changes in the immune system are conditioned by nutrition. European Journal of Clinical Nutrition 2003; 57(Suppl. 1): S66-9.

74 Nova E, Samartin S, Gomez S, Morande G, Marcos A. The adaptive response of the immune system to the particular malnutrition of eating disorders. European Journal of Clinical Nutrition 2002; 56(Suppl. 3): S34-7.

75 Ford ES; National Health and Nutrition Examination Survey. C-reactive protein concentration and cardiovascular disease risk factors in children: findings from the National Health and Nutrition Examination Survey 1999-2000. Circulation 2003; 108: 1053-8.

76 Warnberg J, Nova E, Moreno LA, Romeo J, Mesana MI, Ruiz $\mathrm{JR}$, et al. Inflammatory proteins are related to total and abdominal adiposity in a healthy adolescent population: the AVENA Study. American Journal of Clinical Nutrition 2006; 84: 505-12.

77 De Ferranti SD, Gauvreau K, Ludwig DS, Newburger JW, Rifai N. Inflammation and changes in metabolic syndrome abnormalities in US adolescents: findings from the 1988-1994 and 1999-2000 National Health and Nutrition Examination Surveys. Clinical Chemistry 2006; 52: 1325-30.

78 Aeberli I, Molinari L, Spinas G, Lehmann R, l'Allemand D, Zimmermann MB. Dietary intakes of fat and antioxidant vitamins are predictors of subclinical inflammation in 
overweight Swiss children. American Journal of Clinical Nutrition 2006; 84: 748-55.

79 King DE, Egan BM, Geesey ME. Relation of dietary fat and fiber to elevation of C-reactive protein. American Journal of Cardiology 2003; 92: 1335-9.

80 Wärnberg J. Inflammatory status in adolescents; the impact of health determinants such as overweight and fitness. PhD thesis, University Press, Stockholm, Sweden, 2006.

81 Snyder EE, Walts B, Perusse L, Chagnon YC, Weisnagel SJ, Rankinen T, Bouchard C. The human obesity gene map: the 2003 update. Obesity Research 2004; 12: 369-439.

82 Chen W, Li S, Cook NR, Rosner BA, Srinivasan SR, Boerwinkle E, et al. An autosomal genome scan for loci influencing longitudinal burden of body mass index from childhood to young adulthood in white sibships: The Bogalusa Heart Study. International Journal of Obesity and Related Metabolic Disorders 2004; 28: 462-9.

83 Croll JK, Neumark-Sztainer D, Story M. Healthy eating: what does it mean to adolescents? Journal of Nutrition Education 2001; 33: 193-8.

84 Shepherd R, Dennison CM. Influences on adolescent food choice. Proceedings of the Nutrition Society 1996; 55: $345-57$.

85 Popper R, Kroll JJ. Conducting sensory research with children. Journal of Sensory Studies 2005; 20: 75-87.

86 Birch LL, Fisher JO. Development of eating behaviors among children and adolescents. Pediatrics 1998; 101: 539-49.

87 Story M, Neumark-Sztainer D, French S. Individual and environmental influences on adolescents eating behaviors. Journal of the American Dietetic Association 2002; 102(3 Suppl.): S40-51.

88 Brown K, McIlveen H, Strugnell C. Nutritional awareness and food preferences of young consumers. Nutrition $\mathcal{E}$ Food Science 2000; 30: 230-5.

89 Warwick J, McIlveen H, Strugnell C. Food choices of 9-17year olds in Northern Ireland - influences and challenges. Nutrition \& Food Science 1999; 29: 229-36.

90 Carbone ET, Campbell MK, Honess-Morreale L. Use of cognitive interview techniques in the development of nutrition surveys and interactive nutrition messages for

\section{Appendix - HELENA Study Group}

Co-ordinator: Luis A Moreno.

Core Group members: Luis A Moreno, Fréderic Gottrand, Stefaan de Henauw, Marcela González-Gross, Chantal Gilbert.

Steering Committee: Anthony Kafatos (President), Luis A Moreno, Christian Libersa, Stefaan de Henauw, Jackie Sánchez, Fréderic Gottrand, Mathilde Kersting, Michael Sjöstrom, Dénes Molnár, Marcela González-Gross, Jean Dallongeville, Chantal Gilbert, Gunnar Hall, Lea Maes, Luca Scalfi.

Project Manager: Pilar Meléndez.

Universidad de Zaragoza (Spain): Luis A Moreno, Jesús Fleta, José A Casajús, Gerardo Rodríguez, Concepción Tomás, María I Mesana, Germán Vicente-Rodríguez, Adoración Villarroya, Carlos M Gil, Ignacio Ara, Juan Revenga, Carmen Lachen, Juan Fernández, Gloria Bueno, low-income populations. Journal of the American Dietetic Association 2002; 102: 690-6.

91 Jimenez-Cruz A, Gutierrez-Gonzalez AN, Bacardi-Gascon M. Low glycemic index lunch on satiety in overweight and obese people with type 2 diabetes. Nutrición Hospitalaria 2005; 20: 348-50.

92 Brand-Miller JC. Glycemic load and chronic disease. Nutrition Reviews 2003; 61(5Pt2): S49-55.

93 Ebbeling CB, Leidig MM, Sinclair KB, Hangen JP, Ludwig DS. A reduced-glycemic load diet in the treatment of adolescent obesity. Archives of Pediatrics \& Adolescent Medicine 2003; 157: 773-9.

94 Agus MS, Swain JF, Larson CL, Eckert EA, Ludwig DS. Dietary composition and physiological adaptations to energy restriction. American Journal of Clinical Nutrition 2000; 71: 901-7.

95 Contento I, Balch GI, Bronner YL. The effectiveness of nutrition education and implications for nutrition education policy, programs and research. Journal of Nutrition Education 1995; 13: 1-11.

96 Lytle LA, Jacobs DR, Perry CL, Klepp K-I. Achieving physiological change in school-based intervention trials: what makes a preventive intervention successful? British Journal of Nutrition 2002; 88: 219-21.

97 De Bourdeaudhuij I, Sallis J, Vandelanotte C. Tracking and explanation of physical activity from adolescence to young adulthood. A 7-year prospective study. Research Quarterly for Exercise and Sport 2002; 73: 376-85.

98 Manios Y, Moschandreas J, Hatzis C, Kafatos A. Health and nutrition education in primary schools of Crete: changes in chronic disease risk factors following a 6-year intervention programme. British Journal of Nutrition 2002; 88: 315-24.

99 Anderson AS, Cox DN, McKellar S, Reynolds J, Lean MEJ, Mela DJ. Take Five, a nutrition education intervention to increase fruit and vegetables intakes: impact on attitudes towards dietary change. British Journal of Nutrition 1998; 80: $133-40$

100 Nowak M. The weight-conscious adolescent: body image, food intake, and weight-related behaviour. Journal of Adolescent Health 1998; 23: 389-98.

101 Brug J, Oenema A, Campbell M. Past, present and future of computer-tailored nutrition education. American Journal of Clinical Nutrition 2003; 77(4 Suppl.): 1028S-34S.

Aurora Lázaro, Olga Bueno, Juan F León, Jesús Ma Garagorri, Manuel Bueno.

Consejo Superior de Investigaciones Científicas (Spain): Ascensión Marcos, Julia Wärnberg, Esther Nova, Sonia Gómez, Esperanza Ligia Díaz, Javier Romeo.

Université de Lille 2 (France): Laurent Beghin, Christian Libersa, Frédéric Gottrand.

Research Institute of Child Nutrition Dortmund, Rbeinische Friedrich-Wilbelms-Universität Bonn (Germany): Mathilde Kersting, Wolfgang Sichert-Hellert, Ellen Koeppen.

Pécsi Tudományegyetem (University of Pécs) (Hungary): Dénes Molnár, Eva Erhardt, Katalin Csernus, Katalin Török, Szilvia Bokor, Mrs. Angster, Enikö Nagy, Orsolya Kovács, Judit Répasi.

University of Crete School of Medicine (Greece): Anthony Kafatos, Caroline Codrington, Angeliki Papadaki, Maria Plada, Maria Skourboulianaki, Katerina Sarri, 
Joanna Moschandreas, Christos Hatzis, Manolis Linardakis, Constantine Vardavas, Froso Bervanaki, Anna Viskadourou.

Institut für Ernäbrungs- und Lebensmittelwissenschaften - Humanernäbrung, Rbeinische Friedrich Wilbelms Universität (Germany): Peter Stehle, Klaus Pietrzik, Marcela González-Gross, Christina Breidenassel, Andre Spinneker, Jasmin Al-Tahan, Miriam Segoviano, Christine Bierschbach, Erika Blatzheim, Adelheid Schuch, Petra Pickert.

University of Granada (Spain): Manuel J Castillo Garzón, Ángel Gutiérrez Sáinz, Jonatan Ruiz Ruiz, Francisco B Ortega Porcel, Enrique García Artero, Francisco Carreño Gálvez, Vanesa España Romero, Cristóbal Sánchez Muñoz.

Istituto Nazionale di Ricerca per gli Alimenti e la Nutrizione (Italy): Davide Arcella, Giovina Catasta, Laura Censi, Donatella Ciarapica, Marika Ferrari, Cinzia Le Donne, Catherine Leclercq, Luciana Magrì, Giuseppe Maiani, Rafaela Piccinelli, Angela Polito, Raffaella Spada, Elisabetta Toti.

University of Napoli 'Federico II, Department of Food Science (Italy): Luca Scalfi.

Ghent University (Belgium): Ilse de Bourdeaudhuij, Stefaan de Henauw, Mieke de Maeyer, Tineke de Vriendt, Lea Maes, Christophe Matthys, Charlene Ottevaere, Carine Vereecken.

Medical University of Vienna (Austria): Kurt Widhalm, Katharina Phillipp, Sabine Dietrich.

Harokopio University (Greece): Yannis Manios, Eva Grammatikaki, Zoi Bouloubasi, Tina Louisa Cook, Sofia Eleutheriou, Orsalia Konsta, George Moschonis, Ioanna Katsaroli, George Kraniou, Stalo Papoutsou, Despoina Keke, Ioanna Petraki, Elena Bellou, Sofia Tanagra, Kostalenia Kallianoti, Diongsia Arggropoulou, Katerina Kondaki, Stamatoula Tsikrika, Christos Karaiskos.

Institut Pasteur de Lille (France): Jean Dallongeville, Aline Meirhaeghe.
Karolinska Institutet (Sweden): Michael Sjöstrom, Patrick Bergman, María Hagströmer, Lena Hallström, Mårten Hallberg, Eric Poortvliet, Julia Wärnberg, Linda Bergman, Anita-Hurtig Wennlöf, Lars Cernerud.

Asociación de Investigación de la Industria Agroalimentaria (Spain): Jackie Sánchez-Molero, Elena Picó, Maite Navarro, Blanca Viadel, José Enrique Carreres, Gema Merino, Rosa Sanjuán, María Lorente, María José Sánchez.

Campden \& Chorleywood Food Research Association (UK): Chantal Gilbert, Sarah Thomas, Peter Burgess.

SIK - Institutet foer Livsmedel och Bioteknik (Sweden): Annika Astrom, Gunnar Hall.

Meurice Recherche \& Development asbl (Belgium): Annick Masson, Claire Lehoux, Pascal Brabant, Philippe Pate, Laurence Fontaine.

Campden \& Chorleywood Food Development Institute (Hungary): Andras Sebok, Tunde Kuti, Adrienn Hegyi.

Productos Aditivos SA (Spain): Cristina Maldonado, Ana Llorente.

Cárnicas Serrano SL (Spain): Carlos Valero.

Cederroth International AB (Sweden): Holger von Fircks, Marianne Lilja Hallberg.

Cerealia RED AB (Sweden): Mats Larsson, Helena Fredriksson, Viola Adamsson, Ingemar Gröön, Ingmar Börjesson.

European Food Information Council (Belgium): Laura Fernández.

Universidad Politécnica de Madrid (Spain): Marcela González-Gross, Agustín Meléndez, David JiménezPavón, Jara Valtueña, Paloma Navarro, Alejandro Urzanqui, Ulrike Albers, Raquel Pedrero. 